\title{
FAST ELECTROCHEMICAL DETECTION OF NON-DESIRABLE AGING IN BOTTLED WHITE WINE
}

\author{
M.J. AGUIRRE ${ }^{*}$, J.P. MUENA', D. GONZALEZ-ULIANOFF', A. MIRANDA \\ ${ }^{I}$ Departamento de Química de los Materiales, Facultad de Química y Biología, Universidad de Santiago de Chile, USACH. \\ Av. B. O'Higgins 3363, Estación Central, Santiago, Chile. \\ 2 Servicios y Asesorias Excell Sudamérica S.A., Magdalena 275, Las Condes, Santiago, Chile.
}

\begin{abstract}
Oenologists and wine exporters know that a serious problem is to determine the quality of wine after it travels to final market. In fact the last quality controls are made after the bottling and before the trip. Chile is an important exporter of wine and Asiatic markets are a common destination for this exportation, taking long times of traveling. If wine changes it quality due to different stressing situations during the trip, the final costumer will receive a low-quality beverage in spite of the high quality of the original wine. This fact can reduce the interest of the costumer to consume Chilean wine and diminishes the importations of this product.
\end{abstract}

\section{INTRODUCTION}

Electrochemical methods can be key to measure if wine has suffered chemical changes during the trip, because this kind of methods is inexpensive and easy to operate. In this sense different amperometric sensors are developed to measure sulfur dioxide (the most important wine preservative) or different phenols in model wine ${ }^{1-10}$. However the goal is not achieved due the high complexity of different wines. On the other hand, very sophisticated methods have been developed to measure different components of wine. One of the most common methods is HPLC-mass spectrometry or gas cromatography that can be used normally after liquid extraction of different family compounds from the wine ${ }^{11-15}$. The complexity of the analysis requires multivariate statistical approaches, including canonical variate analysis ${ }^{16}$. Different aging factors such as temperature of storage, oxygen addition, movement, light exposure and others $^{14,15,17}$ can affect the aroma and flavor of wines.

Our aim is to develop a very easy, fast and inexpensive way to only determine if wine has suffered undesirable aging or not. Electrochemical methods like cyclic voltammetry have been used for determining some characteristics of wine like antioxidant capacity of some phenols or the sulfite concentration $^{10,12,18-20}$.

However, at our knowledge, these methods have not been used to measure some aging effects on wine.

It is the first report of using directly square wave voltammetry to determine if wine has been exposed to factors of aging. The idea is to develop an easy to operate method that can be adapted for using during and after the travel by non specialist persons.

In this work bottled white wine was subjected to temperatures greater and lesser than cellar temperatures and exposed to light and motion. Thermostated baths (EX-300DD Neslab instrument), orbital shakers (OS-100, CE instruments, 50 and $100 \mathrm{rpm}$ ) and white lamps (LED) were used for these purposes. After exposition to one of these factors, wine was measured by cyclic voltammetry and square wave voltammetry using a bipotentiostat (CHI-900B $\mathrm{CH}$ Instruments) at different potential ranges in order to determinate if some replicable change can be measured and attributed to a specific perturbation. Wine was measured as received, without electrolyte and at their $\mathrm{pH}(\mathrm{pH} 3.5)$. All the measurements were done in a thermostatic cell at $20 \square \mathrm{C}$ of different wines kept during 24 hours in the cellar after the perturbation and after wine reaches $20 \square$ C. Control wine is the same wine (same origin but kept in the cellar during all the time after being received.)

Fig. 1 shows the voltammetric response of white wine after being exposed to high temperatures ( $30 \square \mathrm{C}$ ) during a week, compared to the response of the control wine. It is clear from this Fig. that the change in the response is very little and cyclic voltammetry is not an appropriate technique to measure this kind of changes.

However, a more perceptible change can be observed using square wave voltammetry as shown in Fig.2.

In this Fig. is possible to see that the potential where the peak appears is shifted to more negative values from 0.128 to $0.076 \mathrm{~V}$ when wine is heated to $30 \square \mathrm{C}$. The change of the potential of the peaks is slight but is reproducible and repeatable for the same wine and for the same treatment. In this case, the change corresponds to a shift of $0.05 \mathrm{~V}$ to more negative potentials. The changes between the profile corresponding to the heated wine or the cooled wine are slight but easy to detect. In the last case, the potential of the peak shifts from $0.0128 \mathrm{~V}$ to $0.012 \mathrm{~V}$. Also, the plateau slightly increases in current for the heated wine and, in the case of the cooled wine, it maintains the current. Also, a change is observed in the relative intensity and pattern of the shoulder (right side of the peak) compared to the control.

However, the peaks are not clearly defined and it is not possible to deconvolute these wide peaks because it is not known how many processes correspond to each wave. Also, a high difference in the background current is observed. This difference is not understood at this moment. On the other hand, these oxidation processes are difficult to be observed when cyclic voltammetry is employed, as shown in Fig.1.

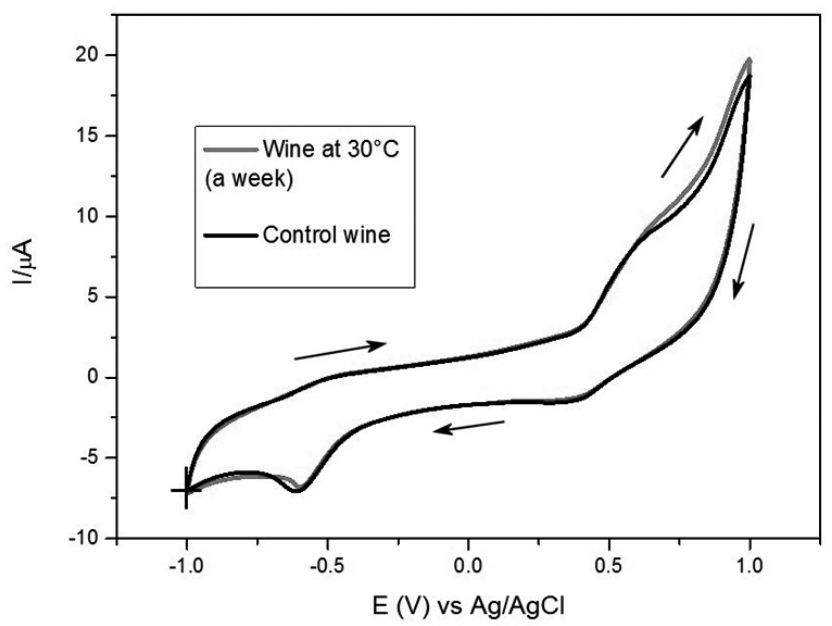

Figure 1. Voltammetric response of control or heated wine. $100 \mathrm{mVs}^{-1}$. Glassy carbon is the work electrode. Solution exposed to air.

In the case of other kind of aging factors, the square wave voltammetry depicts other characteristics. Although the potential corresponding to the maximum is poorly-defined and that the use of three decimals has no analytical sense, it is necessary to use these decimals using always the same fixed protocol (maximum of the Origin 9.1 program, in this case). The use of the protocol to determine the potential is necessary to determine the observed slight displacements.

However, in each case studied here, is possible to observe some changes adopting a characteristic pattern that can be attributed to a specific treatment. The voltammetric profile of a determined wine kept at $14 \square \mathrm{C}$ in horizontal position maintains. The response for the control wine is reproducible. This is the most important finding of this work. Then, it is possible to have a control pattern to compare before and after of the trip. It is important to mention that the voltammetric profile changes for each specific kind of wine regardless of the source and type of grapes. Then, it is necessary to obtain the profile of the wine that will be transported both before and after the trip. The change in this profile is a measure of the aging of the wine.

It is necessary to pointed out that is impossible to use the voltammetric methods in a direct way for obtaining "quantitative" aging (time of exposure). 
This method works just like a switch: it only reports if the wine has been exposed or not to the change in temperature. Indeed, the change of the shoulder is the most significant behavior for the heated or the cooled wine.

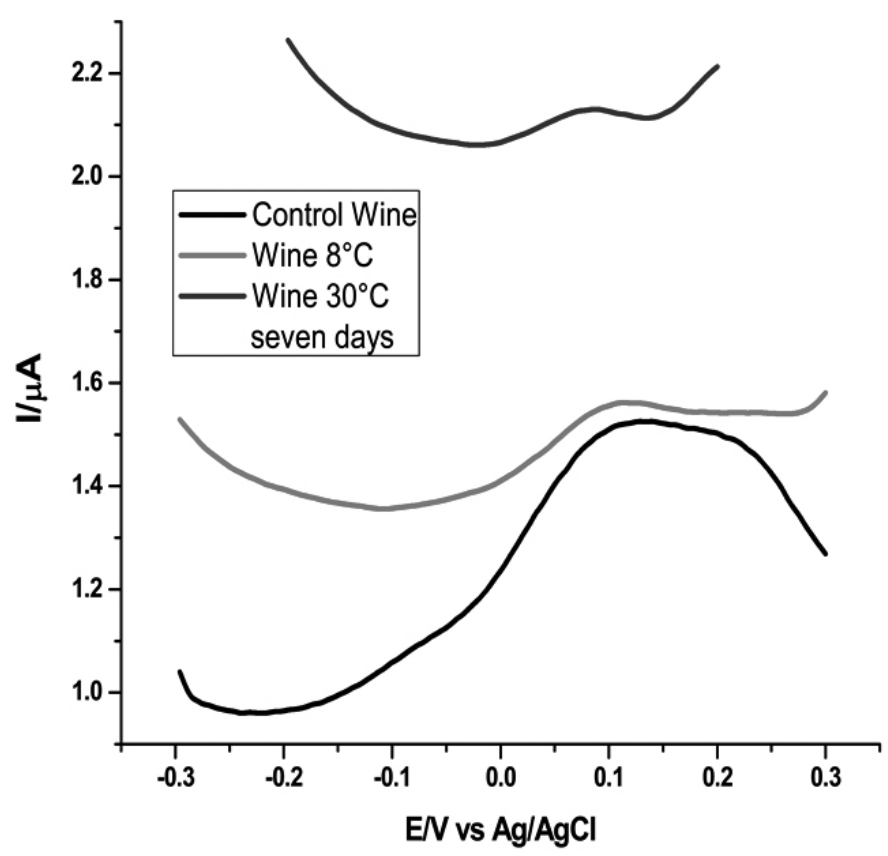

Figure 2. Square wave voltammetric profiles of the control, heated and cooled wine. (increment: $0.004 \mathrm{~V}$; amplitude: $0.025 \mathrm{~V}$; frequency: $15 \mathrm{~Hz}$ ).

Fig. 3 shows the response of a wine that was sonicated during 15 minutes. Now, a wide plateau appears between 0.016 and $0.284 \mathrm{~V}$. As mentioned before, the square wave voltammetry can detect if a wine has been or has not been agitated. Also, the method discriminates between the effect of sonication or a shaker (100 rpm) (not shown).

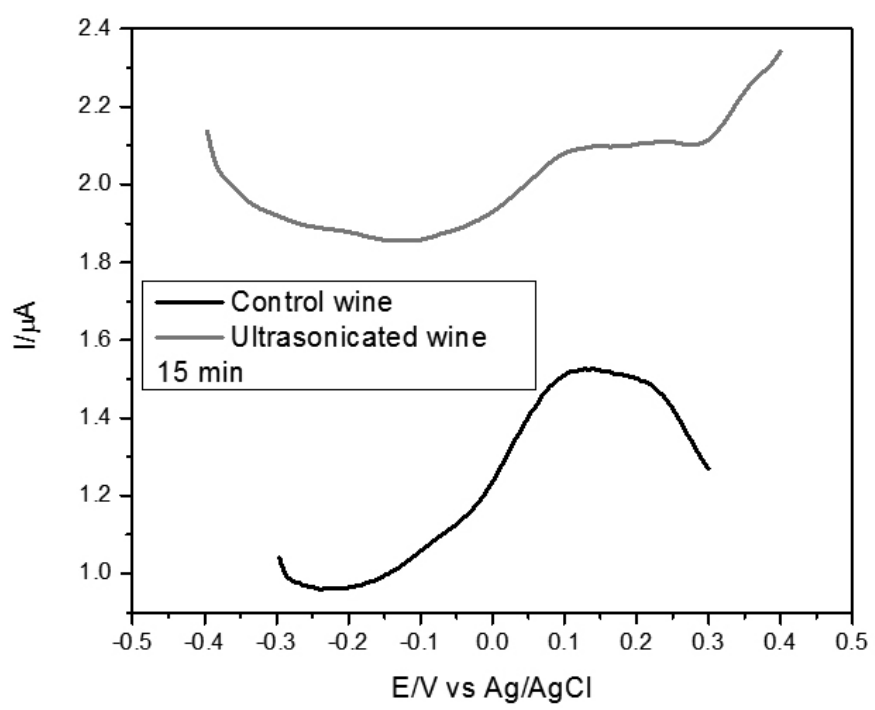

Figure 3. Square wave voltammetric profiles of control and sonicated wine. (increment: $0.004 \mathrm{~V}$; amplitude: $0.025 \mathrm{~V}$; frequency: $15 \mathrm{~Hz}$ ).

On the other hand, it is feasible to use the cyclic voltammetry in order to quantify a determined phenol, as in the case or gallic acid, resveratrol or others, using the standard addition method and considering that a series of phenols has been measured (oxidation waves) using model wines $(0.05 \mathrm{M}$ tartaric acid; $12 \%$ $\mathrm{v} / \mathrm{v}$ etanol/water; $0.1 \mathrm{M}$ sodium perchlorate)

In this sense, we measured the gallic acid, sulfite and adduct between gallic acid and sulfite, adding different aliquots of known concentration of each species to a diluted wine solution ( $25 \% \mathrm{v} / \mathrm{v}$ wine/model wine) (not shown). Figure 4 shows the square wave voltammetry of resveratrol added to a white wine diluted solution.

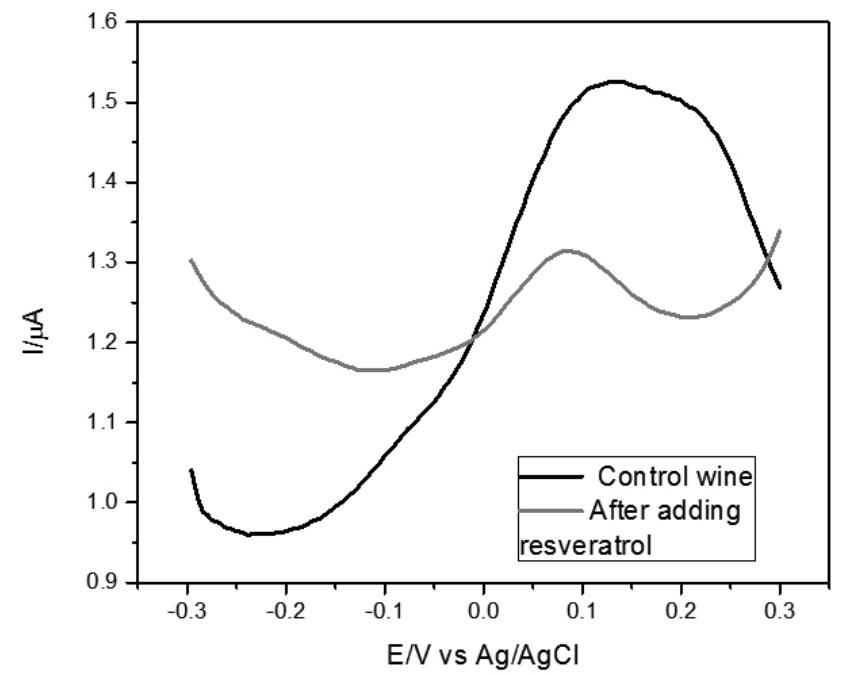

Figure 4. Square wave voltammetric profiles of white wine kept in the cellar and the same wine but after addition of resveratrol. (increment: $0.004 \mathrm{~V}$; amplitude: $0.025 \mathrm{~V}$; frequency: $15 \mathrm{~Hz}$ )

This Fig. depicts the chemical behavior of a phenol. When the cyclic voltammetry is performed, an irreversible oxidation wave appears in the range of positive potentials permitted by the solvent and the electrode. This oxidation wave increases in current linearly with the concentration of the phenol. Then, applying square wave voltammetry or differential pulse voltammetry, it is easy to obtain a calibration straight line $\left(\mathrm{y}(\mathrm{mA} \mathrm{cm}-2)=0.188 \mathrm{C}\left(\mathrm{mA} \mathrm{cm}^{-2} \mathrm{mM}^{-1}\right)-\right.$ $0.0087, \mathrm{R}=0.997$ ) for measuring this phenol directly or, better, to obtain the intercept value for standard addition method.

\section{CONCLUSIONS}

We present a qualitative analysis to determine if the wine has suffered an aging situation by using square wave voltammetry. Although the method is not quantitative, it can directly measure the wine without requiring sophisticated separation techniques. The method works as a switch indicating if the wine has been or has not been subjected to situations of aging. It can discriminate among different situations but requires to have a reproducible voltammetric profile of the wine kept in the cellar.

\section{ACKNOWLEDGEMENTS}

Authors acknowledge Fondecyt 1120071 project and Aporte Basal por Desempeño Mecesup Basal project.

\section{REFERENCES}

1. P. Bravo, Y.Y Chen, G. Ramírez, M.J. Canales, B. Matsuhiro, L. Mendoza, M. Isaacs, M. García, M.C. Arévalo, M.J. Aguirre C. C. C. C. 74, 545, (2009)

2. G. Ramírez, M.C. Goya, L. Mendoza, B. Matsuhiro, M. Isaacs, Y.Y. Chen, M. Arévalo, J. Henríquez, W. Cheuquepán, M.J. Aguirre, J. Coord. Chem. 62, 2782, (2009)

3. K. Kalfuman, M.J. Aguirre, D. Villagra, C. Yañez, C. Arévalo, B. Matsuhiro, L. Mendoza, M. Isaacs, J. Sol. Stat. Electrochem. 14, 1065 , (2010)

4. K. Kalfuman, M. García, M.J. Aguirre, B. Matsuhiro, L. Mendoza, M. Isaacs, Electroanal. 22, 338, (2010)

5. J. Velez, J.P. Muena, M.J. Aguirre, G. Ramirez, F. Herrera, Int. J. Electrochem. Sci. 7, 3167, (2012) 
6. M. Lucero, M. Riquelme, G. Ramirez, M. Goya, A.G. Orive, A.H. Creus, M.C. Arevalo, M.J. Aguirre, M. Isaacs, L. Mendoza, Int. J. Electrochem. Sci. 7, 234, (2012)

7. L. Mendoza, B. Matsuhiro, M.J. Aguirre, M. Isaacs, G. Sotes, M. Cotoras, M. Ricardo, J. Chil. Chem. Soc. 56, 688, (2011)

8. M.J. Aguirre, M. Isaacs, B. Matsuhiro, L. Mendoza, L.S. Santos, S. Torres, Food Chem. 129, 514, (2011)

9. A. Tuerke, W.J. Fischer, N. Beaumont, P.A. Kilmartin, Electrochim. Acta, 60, 184 (2012)

10. M. Schneider, A. Türke, W.J. Fischer, P. A. Kilmartin, Food Chem. 159 $428,(2014)$

11. B. Matsuhiro, R. Torres, E.A. Zuñiga, M.J. Aguirre, L. Mendoza, M. Isaacs, J. Chil. Chem. Soc. 54, 405, (2009)

12. O. Makhotkina, P.A. Kilmartin, J. Agric. Food Chem. 61, 5573, (2013)
13. F. Benkwitz, T. Tominaga, P.A. Kilmartin, C. Lund, M. Wohlers, L. Nicolau, Am. J. Enol. Vitic. 63, 62, (2012)

14. O. Makhotkina, B. Pineau, P.A. Kilmartin, Aust. J. Grape Wine Res, 18, 91, (2012)

15. C. Coetzee, K. Lisjak, L. Nicolau, P. Kilmartin, W.J. du Toit, Flavour Frag. J. 28, 155, (2013)

16. F. Benkwitz, L. Nicolau, C. Lund, M. Beresford, M. Wohlers, P.A. Kilmartin, J. Agric. Food Chem. 60, 6293, (2012).

17. O. Makhotkina, P.A. Kilmartin, Food Chem. 135, 486, (2012)

18. M.J. Aguirre, Y.Y. Chen, M. Isaacs, B. Matsuhiro, L. Mendoza, S. Torres, Food Chem. 121, 44, (2010)

19. P.A. Kilmartin, H. Zou, A.L. Waterhouse J. Agric. Food. Chem. 49, 1957, (2001)

20. C. Montes, J.H. Velez, G. Ramirez, M. Isaacs, R. Arce, M.J. Aguirre, ScientificWorldJournal, 168148. doi: 10.1100/2012/168148. (2012). 